$\mathrm{H}$ у пациентов с экскориированными акне

Ильчевская Е. А. ${ }^{1}$, Криницына Ю. М. ${ }^{1},{ }^{2}$, Сергеева И. Г. ${ }^{1}$

${ }^{1}$ Новосибирский национальный исследовательский государственный университет
630090, Российская Федерация, г. Новосибирск, ул. Пирогова, д. 1
${ }^{2}$ Институт молекулярной патологии и патоморфологии
630117, Российская Федерация, г. Новосибирск, ул. Тимакова, д. 2

В статье приводится анализ психопатологических особенностей пациентов с экскориированными акне. Среди 43 пациентов (средний возраст 24,7 7, 1 года) интегративный тест тревожности показал пограничные значения и высокий уровень личностной тревоги в 46,5\% случаев; оценка по шкале депрессии Бека - субдепрессию у 25,6\% пациентов и депрессию - у 13,9\%; общий индекс тяжести (GSI) симптоматического опросника SCL-90-R был в зоне повышенных и высоких значений у 31,1\%. Наибольшие отклонения от нормы были в сорерах межличностной сенситивности - у 34,9\% пациентов, фробической тревожности - у 30,2\%, паранойяльности - у 30,2\%, соматизации жалоб у 27,9\%. Субшкала обсессии-компульсии была выше нормативных значений у 21\% больных.

Ключевые слова: экскориированные акне, тревожность, депрессия, изотретиноин

Конфрликт интересов: авторы заявляют об отсутствии потенциального конфрликта интересов, требующего раскрытия в данной статье.

Для цитирования: Ильчевская Е. А., Криницына Ю. М., Сергеева И. Г. Нарушения психоэмоционального статуса у пациентов с экскориированными акне. Вестник дерматологии и венерологии. 2017;(5):64-69.

DOI: 10.25208/0042-4609-2017-93-5-64-69 


\title{
Abnormalities of Psycho-Emotional State among Patients with Excoriated Acne
}

Elena A. Il'chevskaya', Yuliya M. Krinitsyna ${ }^{1,2}$, Irina G. Sergeeva ${ }^{1}$

\author{
${ }^{1}$ Novosibirsk State University \\ Pirogova str., 1, Novosibirsk, 630090, Russian Federation \\ 2 Institute of Molecular Pathology and Pathomorphology \\ Timakova str., 2, Novosibirsk, 630117, Russian Federation
}

The psychopathological features of patients with excoriated acne are analysed. An integrative anx-iety test among 43 patients (mean age 24.7 \pm 7.1 years) demonstrated borderline values and a high level of personal anxiety in $46.5 \%$ of cases; assessment according to the Beck Depression Inventory revealed subdepression among $25.6 \%$ and depression among $13.9 \%$ of patients; the Global Severity Index (GSI) of the Symptom Checklist-90-R (SCL-90-R) was in the zone of elevated and high val-ues among $31.1 \%$ of patients. The greatest deviations from the norm were observed in the areas of interpersonal sensitivity among $34.9 \%$ of patients; dev phobic anxiety $-30.2 \%$; paranoia - 30.2\%; while somatisation of complaints was observed among $27.9 \%$ of patients. The obsessive-compulsive subscale exceeded normative values among $21 \%$ of patients.

Keywords: excoriated acne, anxiety, depression, isotretinoin

Conflict of interest: the authors state that there is no potential conflict of interest requiring disclosure in this article.

For citation: Il'chevskaya E. A., Krinitsyna Yu. M., Sergeeva I. G. Abnormalities of Psycho-Emotional State among Patients with Excoriated Acne. Vestnik Dermatologii i Venerologii. 2017;(5):64-69.

DOI: 10.25208/0042-4609-2017-93-5-64-69 


\section{Введение}

Психиатрические и психосоциальные фракторы имеют значение не менее чем в 25-33\% случаях дерматологических заболеваний [1]. Акне, одно из наиболее распространенных кожных заболеваний, часто обостряется на фоне стресса, и в то же время стресс еще более усугубляется при обострении акне [2]. В дальнейшем на первый план выступают социофобия, переживания о внешней непривлекательности, приводящие к социальной самоизоляции [3]. При наличии многочисленных экскориаций, геморрагических корок на фоне легкого течения заболевания необходимо проводить диффреренциальную диагностику вульгарных и экскориированных акне (рубрика L70.5 Международной классификации болезней 10-го пересмотра) [4]. Для характеристики этого варианта самоповреждающего поведения у больных акне также используют другие термины: невротические экскориации, психогенные экскориации, патологическая или компульсивная дерматилломания [5, 6].

Целью настоящего исследования было изучение психопатологических особенностей пациентов с экскориированными акне.

\section{Материалы и методы}

Методом случайной последовательной выборки было отобрано 43 пациента с акне легкой или средней степени тяжести и склонностью к экскориированию, в воз-

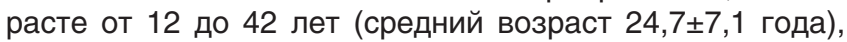
женщин было 36 (83,7\%), мужчин - 7 (16,3\%). Средний

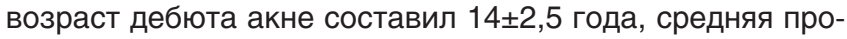

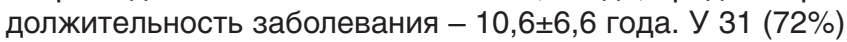
пациента наблюдали легкую степень тяжести акне, у 12 (18\%) - среднюю степень тяжести. Для 27 (62,8\%) пациентов это было первое обращение к врачу по поводу акне, 13 (30,2\%) ранее обращались к дерматологу и 3 (7\%) - к врачам других специальностей (гинеколог, эндокринолог, гастроэнтеролог).

Раз в несколько месяцев экскориировали кожу 8 $(18,6 \%)$ пациентов, не реже 1 раза в месяц - 16 (37,2\%), постоянно (при каждом новом высыпании) - 18 (44,2\%). Пять человек признались, что им доставляет удовольствие экскориировать кожу (выдавливать угри) у других людей, чаще всего партнеров или близких родственников. У 2 пациенток были выявлены последствия других аутодеструктивных действий: у одной в фрорме самопорезов на предплечьях и у второй - в форме трихотилломании в области бровей и ресниц.

При оценке количества экскориаций у пациентов с акне на момент осмотра на коже лица было менее 4 экскориаций у $17(39,6 \%)$ пациентов, 4-9 экскориаций у 18 (41,9\%), 10 и более экскориаций - у 8 (18,6\%).

Психоэмоциональное состояние и уровень дистресса пациентов оценивали с помощью интегративного теста тревожности (ИТТ), шкалы депрессии Бека и симптоматического опросника SCL-90-R. Инструменты использовали в перечисленном порядке в спокойной окружающей обстановке, после инструкции врача.

ИТТ предполагает проведение экспресс-диагностики тревоги и тревожности, имеет 2 шкалы (СТ-С, измеряющую ситуационную тревогу или транзиторное эмоциональное состояние, и СТ-Л, измеряющую личностную тревогу, склонность реагировать на ситуации), а также 5 субшкал для измерения структуры тревоги. Для облегчения процедуры сравнения полученных результатов был осуществлен математический перевод баллов в нормативные - станайны.

Шкала депрессии Бека - опросник, включающий 21 категорию симптомов и жалоб. В соответствии со степенью выраженности симптома каждому пункту присваиваются значения от 0 (симптом отсутствует или выражен минимально) до 3 (максимальная выраженность симптома). Суммарный балл составляет от 0 до 62.

Симптоматический опросник SCL-90-R - клиническая тестовая и скрининговая методика для оценки паттернов психологических признаков у психиатрических пациентов и здоровых лиц. Содержит шкалы: соматизации, обсессивно-компульсивных расстройств (навязчивости), интерперсональной чувствительности, депрессии, тревожности, враждебности, навязчивых страхов (фобии), параноидности (паранойяльности), психотизма. Существует 3 обобщенных индекса дистресса: общий индекс тяжести (GSI), индекс наличного симптоматического дистресса (PSDI) и общее число утвердительных ответов (PST). Индекс GSI является наиболее информативным показателем, отражающим уровень психического дистресса, вычисляется путем деления суммы всех баллов на количество пунктов опросника (норма GSI $\leq 0,8$ балла, повышенные значения - 0,8-1,8 балла, высокие значения индекса - > 1,8 балла).

\section{Результаты}

Ситуативная тревожность согласно данным ИТТ была в пределах нормы у 41 (95,3\%) пациента, у 2 пациенток незначительно отличалась от нормы. Исследование уровня личностной тревожности при помощи ИТТ выявило у 9 (21\%) пациентов высокий уровень тревоги (8 станайнов и выше), у 11 (25,5\%) - пограничные значения тревоги (7 станайнов) и у 23 (53,5\%) - норму. Анализ структуры личностной тревожности (рис. 1) показывает, что у пациентов с экскориированными акне были наиболее выражены отклонения по 3 субшкалам: эмоциональный дискомфрорт (наличие эмоциональных расстройств, сниженный эмоциональный фрон и неудовлетворенность жизненной ситуацией, эмоциональная напряженность с элементами ажитации) - у 23 (53,5\%) пациентов, астенический компонент тревоги (преобладание усталости, расстройств сна, вялости и пассивности, быстрая утомляемость) - у 17 $(39,5 \%)$ пациентов и оценка перспектив (проекция страхов не на текущее положение дел, а в перспективу, общая озабоченность будущим на фоне повышенной эмоциональной чувствительности) - у 17 (39,5\%) пациентов.

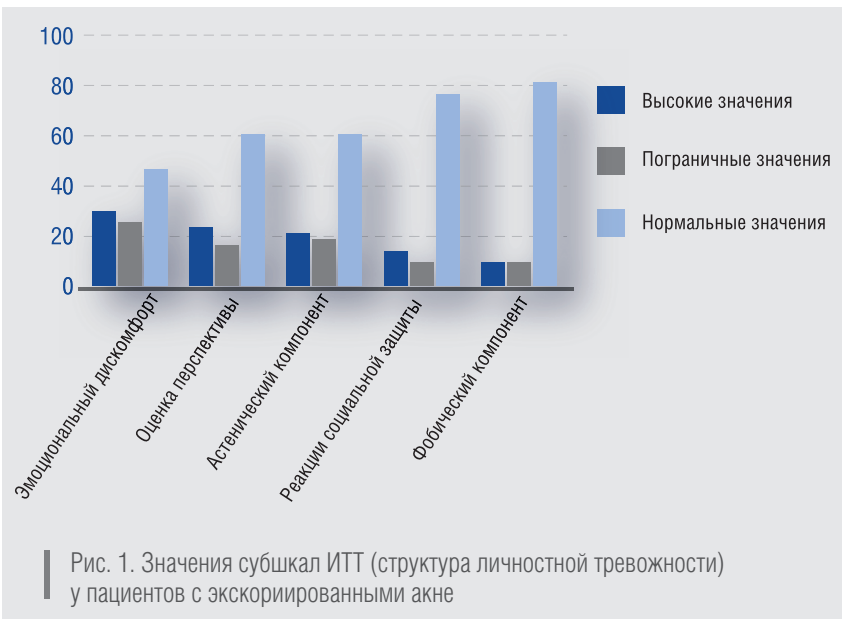




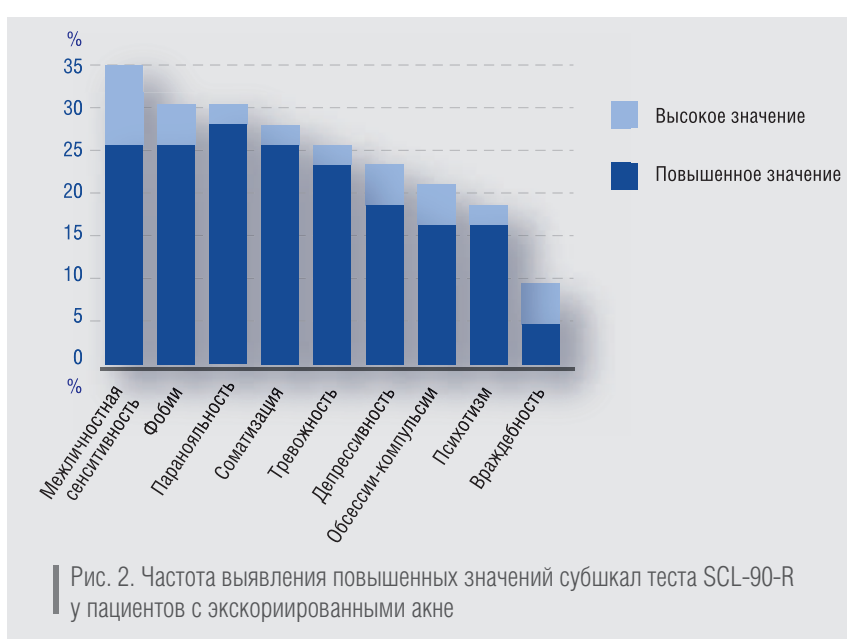

Уровень депрессивности, оцененный по шкале Бека, распределился следующим образом: у 26 (60,5\%) пациентов значения соответствовали норме, у 11 (25,6\%) субдепрессии, не доходящей до степени клинических проявлений, у 4 (9,3\%) - легкой депрессии невротического характера и у 2 (4,6\%) - выраженной депрессии.

По уровню индекса GSI опросника SCL-90-R большинство пациентов - 30 (67,8\%) - были в интервале нормы, 11 $(25,6 \%)$ - в зоне повышенных значений и $2(5,5 \%)$ - в зоне высоких значений. Анализ субшкал опросника SCL-90-R показал наибольшие отклонения от нормы в следующих сорерах: межличностная сенситивность (чувство личностной неполноценности, в особенности когда человек сравнивает себя с другими, самоосуждение, чувство беспокойства и заметный дискомфорт в процессе межличностного взаимодействия) - у 15 (34,9\%) пациентов; фообическая тревожность (стойкая реакция страха на определенных людей, места, объекты или ситуации, ведущая к избегающему поведению) - у 13 (30,2\%); паранойяльность (проективные мысли, враждебность, подозрительность, напыщенность, страх потери независимости, иллюзии) - у 13 $(30,2 \%)$; соматизация (жалобы, фриксированные на кардиоваскулярной, гастроинтестинальной, респираторной и других системах, головные боли, другие боли и дискомфорт общей мускулатуры) - у 12 (27,9\%) (рис. 2). Субшкала обсессии-компульсии (мысли, импульсы и действия, которые переживаются индивидом как непрерывные, непреодолимые и чуждые «Я») имела значения выше нормативных у 9 (21\%) человек.

Для лечения пациентов с экскориированными акне может быть рекомендована терапия изотретиноином [7], так как особенностью данного заболевания, в отличие от патомимии, является обязательное наличие элементов акне на коже. В связи с этим необходимо создать условия для прекращения появления высыпаний. В соответствии с клиническими рекомендациями Российского общества дерматовенерологов и косметологов по терапии акне изотретиноин рекомендуется для терапии форм акне, сопровождающихся выраженными психоэмоциональными расстройствами [8]. Также положительный эфрфект изотретиноина на кожу приводит к улучшению в таких показателях, как депрессия, тревожность, обсессивно-компульсивные симптомы [9].

\section{Клинический случай}

Приводим клиническое наблюдение пациентки Т., 27 лет, страдающей акне с 15-летнего возраста. Пациент- ка профрессионально занимается плаванием, связывала ухудшение состояния кожи с длительным пребыванием в воде. В период применения оральных контрацептивов по поводу гиперандрогении было улучшение состояния кожи, после окончания курса терапии - рецидив заболевания. Пациентка отмечала, что непрерывно экскориирует элементы акне, так как они очень заметны на коже.

Из анамнеза: пациентка работает инструктором по плаванию, после контакта с водой периодически появляются зуд и уртикарные элементы. Несколько месяцев назад делала татуировки, через 12 ч после нанесения второй татуировки были отмечены отек нижней губы и распространенные уртикарные высыпания. Менструации с 13 лет, цикл 28 дней, беременность - 1 (роды в 24 года), до беременности было повышение уровня тестостерона, после беременности - уровень тестостерона в пределах нормальных значений.

При осмотре на коже лица, плеч, надплечий папулезные элементы, эрозии на месте экскориаций, корки, рубцы на месте предшествующих высыпаний (рис. 3). Пациентке был поставлен диагноз: акне экскориированные средней степени тяжести.

Анализ ИТТ показал пограничные значения тревоги (7 станайнов), оценка депрессии по шкале Бека - легкую депрессию невротического характера.

Был назначен изотретиноин в форме LIDOSE (Акнекутан ${ }^{\circledR}$ ) по 0,4 мг/кг в сутки на срок 8 мес с достижением курсовой дозы в 100 мг/кг массы тела. Выбор препарата изотретиноина обусловлен меньшей суточной и курсовой дозой изотретиноина при приеме Акнекутана в связи с большей биодоступностью изотретиноина в препарате (технология LIDOSE) и потенциальным снижением выраженности побочных эффректов относительно препаратов изотретиноина в обычной фрорме выпуска. На фоне терапии прекратили появляться новые высыпания, поэтому пациентка перестала их экскориировать, и через 2 мес терапии определялись только рубцы на месте предшествующих высыпаний (свежих экскориаций не было) (рис. 4). После окончания курса терапии на фоне полного клинического выздоровления наблюдался полный регресс

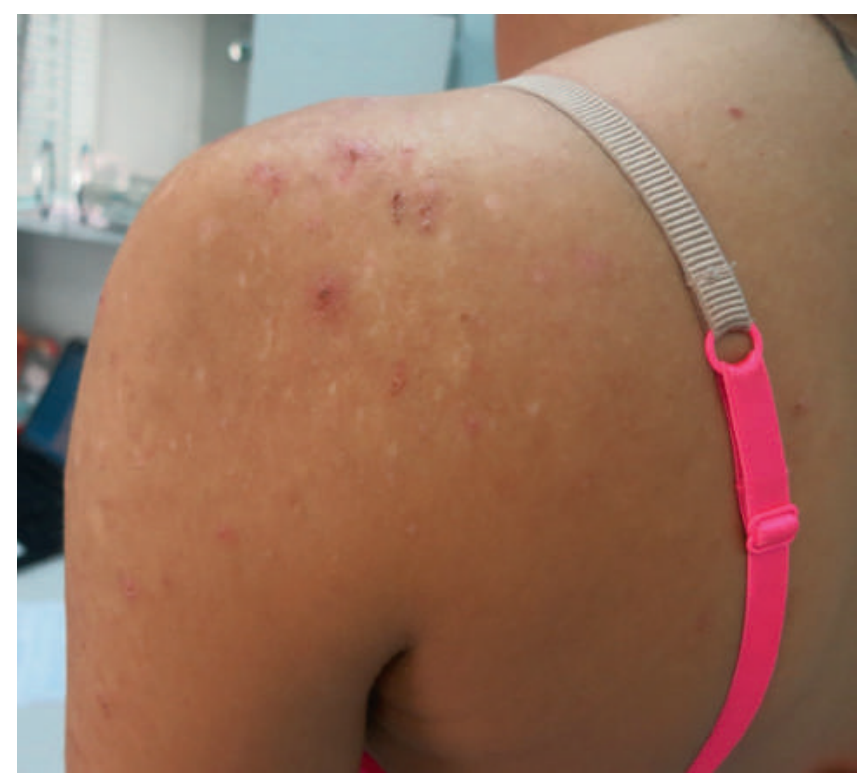

Рис. 3. Состояние кожи спины пациентки Т., 27 лет, до начала терапии 


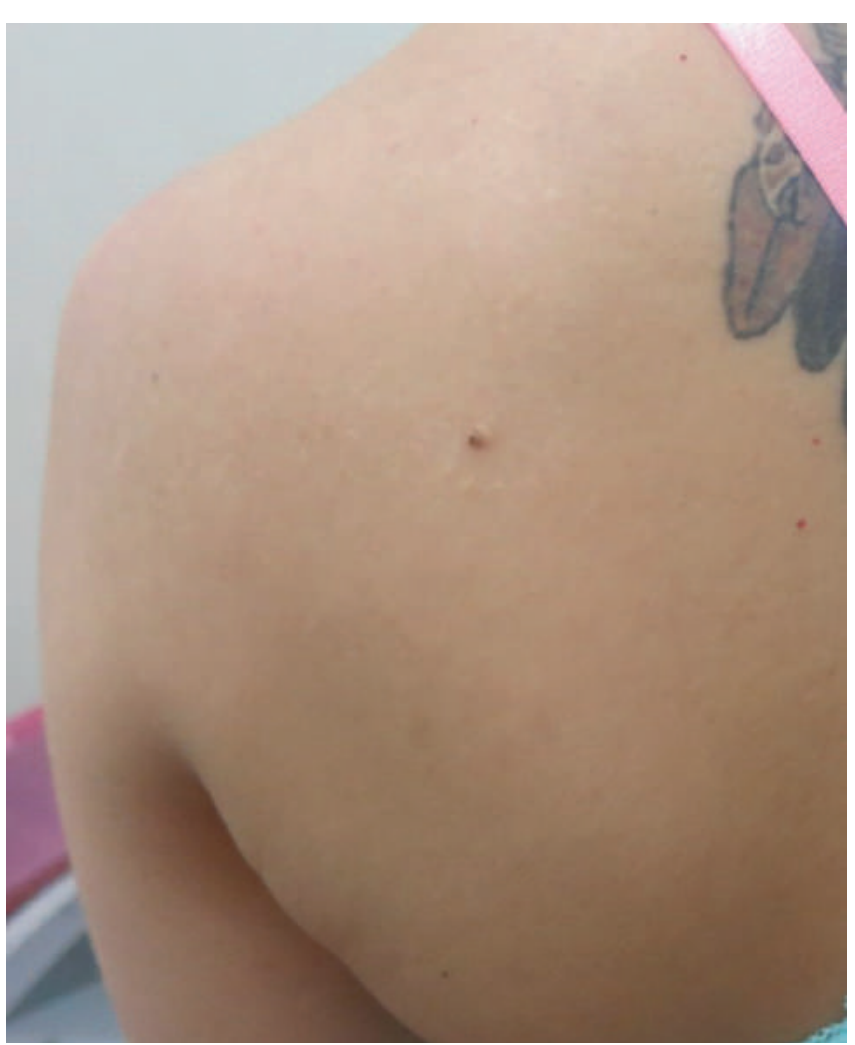

Рис. 4. Состояние кожи спины пациентки Т., 27 лет, через 2 мес от начала терапии изотретиноином LIDOSE в дозе 0,4 мг/кг

склонности к экскориированию кожи (рис. 5). За время длительного курса терапии (8 мес) на фоне раннего достижения хорошего клинического эфрфекта отмечалась нормализация психологического состояния, и после окончания курса показатель ИТТ и уровень депрессии по шкале Бека не отличались от нормальных значений.

\section{Обсуждение}

Экскориированные акне обычно возникают в рамках различных психопатологических френоменов. Нередко пациенты осознают свое деструктивное поведение, вызываемое состоянием напряжения или просто концентрации на чем-то, при этом «атакуется каждый бугорок, дефект, неровность, закрытая пора», привычка ковырять кожу и выдавливать угри осознается как что-то непреодолимое, вызывающее постоянные дерматологические проблемы на протяжении десятилетий [10].

Существуют половые различия в частоте экскориированных акне, соотношение женщин и мужчин для психогенных экскориаций составляет 8:1 [11]. Среди наших пациентов преобладали женщины (83,7\%) в возрасте 20-29 лет (53,49\%). Чаще встречали легкие формы акне (72\%), нередко на прием приходили пациенты без первичных элементов, так как все элементы сыпи были экскориированы (при комедональной форме акне). Оценивая склонность к аутодеструктивным действиям, важно отметить, что подавляющее большинство пациентов $(81,4 \%)$ часто или постоянно прибегали к экскориированию. Нанесение самопорезов на предплечья и выдергивание волос на бровях и ресницах у 2 пациенток в сочетании с экскориациями на лице согласуется с диагностическими критериями трихотилломании и аутодеструктивных кожных заболеваний [12].
Исследование тревожности показало, что ситуативная тревожность (состояние эмоциональной напряженности, обусловленное конкретной ситуацией) имела малый процент отклонений от нормы $(4,7 \%)$, тогда как личностная тревожность (постоянная черта характера, проявляющаяся в склонности индивида испытывать тревогу) у 46,5\% пациентов была выше нормы. Исследование депрессивности выявило 13,9\% случаев с клинически выраженной депрессивной симптоматикой, а у $39,5 \%$ пациентов - отклонения от нормы, включая уровень субдепрессии. Полученные данные близки к указанным в литературе: тревожные расстройства встречаются у 41-65\% пациентов, расстройства настроения - у 48-68\% пациентов [13]. Однако в нашем исследовании тревожные проявления преобладали над расстройствами настроения.

Анализ данных, полученных при помощи симптоматического опросника SCL-90-R, показал значительные отклонения по шкалам межличностной сенситивности, фоббий и паранойяльности, что может объясняться стрессом пациента при пребывании его в социуме в сочетании со сверхценным отношением к своему кожному «дефекту». Описаны обостренная стеснительность, избегающее поведение, сенситивные идеи отношения: в общественных местах, в транспорте, на работе пациенты замечают обращенные на них «особые» взгляды, видят, как люди посмеиваются над ними, обсуждают их внешний вид, поведение, убеждены в том, что окружающие догадываются об их заболевании [3]. Важно отметить, что количество экскориаций на лице и частота экскориирования не зависели от степени выраженности психопатологических симптомов. У женщин были более выражены отклонения от нормы всех показателей: тревожности, депрессивности и общего индекса тяжести симптомов.

\section{Заключение}

Таким образом, при диагностике и лечении акне более важно оценить степень аутодеструктивных действий пациента, чем частоту и количество экскори-

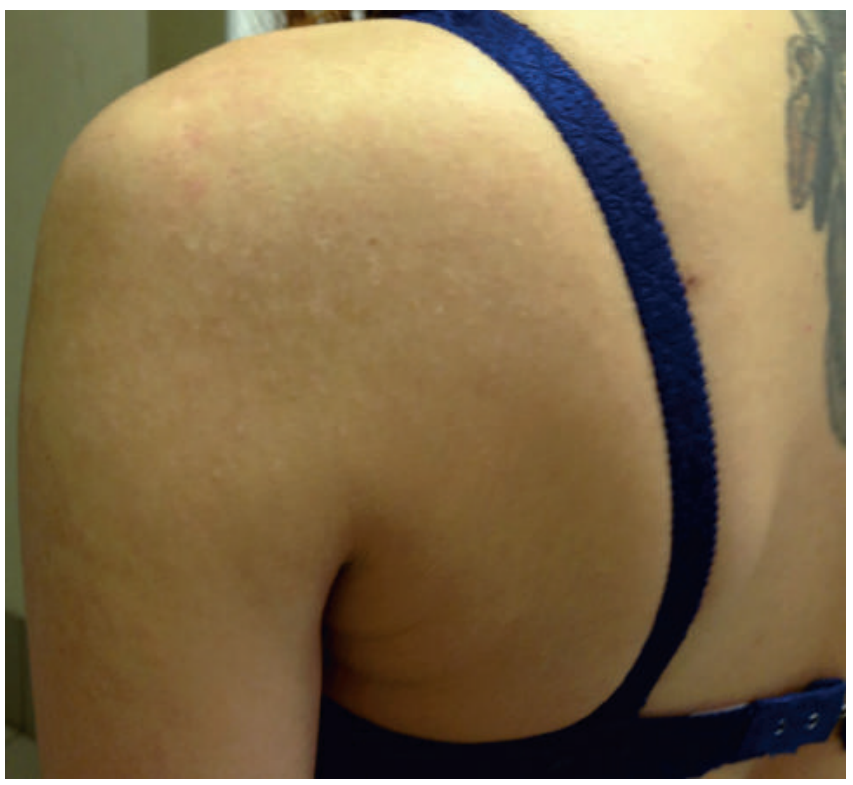

Рис. 5. Состояние кожи спины пациентки Т., 27 лет, после окончания курса терапии (курсовая доза изотретиноина LIDOSE 100 мг/кг) 
аций. Дополнительная психологическая или психиатрическая консультация может помочь в выявлении скрытого психического расстройства, предотвратить симптомы и минимизировать неблагоприятное влияние заболевания на жизнь пациента. Применение системного изотретиноина при терапии пациентов с экскори- ированными формами акне приводит к клинической ремиссии заболевания, за счет чего при своевременном назначении данного вида терапии можно ожидать снижения показателей личностной тревожности и вероятности развития депрессии у данной категории больных.

\section{Литература/References}

1. Gupta M. A., Gupta A. K. The Use of Antidepressant Drugs in Dermatology. J. Eur. Acad. Dermatol. Venereol. 2001;6(15):512-518.

2. Shenefelt P. D. Psychodermatological Disorders: Recognition and Treatment. Int. J. Dermatol. 2011;50(11):1309-1322.

3. Терентьева М. А., Львов А. Н. Клиника и терапия невротических экскориаций. Психиатрия. 2007;1(25):14-26. [Terent'eva M. A., L'vov A. N. Klinika i terapiya nevroticheskih ekskoriacij. Psihiatriya. 2007;1(25):14-26.]

4. Игнатенко И. Е. Аутодеструктивные заболевания кожи: диагностика и принципы ведения больных. Современные проблемы дерматовенерологии, иммунологии и врачебной косметологии. 2013;26(8):41-48. [Ignatenko I. E. Autodestruktivnye zabolevaniya kozhi: diagnostika i principy vedeniya bol'nyh. Sovremennye problemy dermatovenerologii, immunologii i vrachebnoj kosmetologii. 2013;26(8):41-48.]

5. Millsop J. W., Koo J. Acne Excoriée. In: Acneiform Eruptions in Dermatology: A Differential Diagnosis. New York: Springer-Verlag, 2014. P. 111-116.

6. Craig-Müller S. A., Reichenberg J. S. The Other Itch That Rashes: a Clinical and Therapeutic Approach to Pruritus and Skin Picking Disorders. Curr. Allergy Asthma Rep. 2015;15(6):31.

7. Львов А. Н., Кирилюк А. В. Роаккутан в терапии угревой болезни: стандартные режимы терапии и новая схема низких доз. Русский медицин- ский журнал. 2008;16(23):1541-1546. [L'vov A. N., Kirilyuk A. V. Roakkutan v terapii ugrevoj bolezni: standartnye rezhimy terapii i novaya skhema nizkih doz. Rossijskij medicinskij zhurnal. 2008;16(23):1541-1546.]

8. Федеральные клинические рекомендации по ведению больных акне. М.: РОДВК, 2015. 23 с. [Federal'nye klinicheskie rekomendacii po vedeniyu bol'nyh akne. M.: RODVK, 2015. 23 s.]

9. Yesilova Y., Bez Y., Ari M. et al. Effects of Isotretinoin on Obsessive Compulsive Symptoms, Depression, and Anxiety in Patients with Acne Vulgaris. J. Dermatolog. Treat. 2012;23(4):268-271.

10. Acne Excoriée - a Patient's View. J. Cosmet. Dermatol. 2004;3(3):176.

11. Arnold L. M., Auchenbach M. B., McElroy S. L. Psychogenic Excoriation: Clinical Features, Proposed Diagnostic Criteria, Epidemiology and Approaches to Treatment. CNS Drugs. 2001;15(5):351-9.

12. Grant J. E., Stein D. J. Body-focused Repetitive Behavior Disorders in ICD-11. Rev. Bras. Psiquiatr. 2014;36(Suppl 1):59-64.

13. Wilhelm S., Keuthen N. J., Deckersbach T. et al. Self-injurious Skin Picking: Clinical Characteristics and Comorbidity. J. Clin. Psychiatry. 1999;60(7):454-459.

\section{Информация об авторах}

Елена Александровна Ильчевская - интерн, Центр постдипломного медицинского образования Института медицины и психологии Новосибирского национального исследовательского государственного университета

Юлия Михайловна Криницына - д.м.Н., профрессор, главный научный сотрудник, Институт молекулярной патологии и патоморфологии; профрессор кафедры фундаментальной медицины, Институт медицины и психологии Новосибирского национального исследовательского государственного университета

Ирина Геннадьевна Сергеева - д.м.н., доцент, просрессор кафедры фундаментальной медицины, Институт медицины и психологии Новосибирского национального исследовательского государственного университета; директор, Центр постдипломного медицинского образования; e-mail: i_g_sergeeva@mail.ru 